\title{
Facilitators Note Book
}

At the 1997 Australian Outdoor Education Conference, I presented a workshop which highlighted a variety of debriefing techniques that could be used to help students reflect on their adventure experiences. All the ideas that I presented had been picked up over the years from observing colleagues working with groups in the field. I felt that sharing this information could ultimately improve the leaming of students involved in our programs. Now, I would like to encourage all those involved in adventure programming to share their debriefing ideas for all to leam from.

I believe, that out there in the bush every week, most of us are using a variety of "tools" to help facilitate our participant's experiences. I think it would be great if we could share these ideas with each other through this journal page each issue. I would like to propose, that if you have a debriefing activity that you would like to share with readers of this journal, then send it to me at the following address. Ian Boyle, Glengarry, Kangaroo Valley, NSW. 2577. The articles will then become a regular part of the journal for all to read and learn from. My ultimate goal would be to receive enough quality submissions to compile into a volume that could become a resource book of debriefing strategies. Keeping with the spirit of collegial sharing that Mike Gass encouraged with his "Book of Metaphors", anyone contributing a submission will receive a free copy of the book when it is published.

So here is the first entry to "The Facilitators Notebook". The following format may help organise your thoughts.
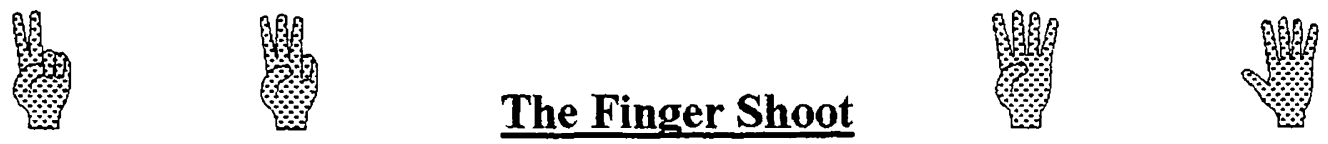

Introduction The finger shoot is a quick and easy way to get participants to reflect on, and quantifiably evaluate their performance or feelings during any part of an adventure experience. It can be used in a variety of ways ranging from a simple check in with group members to see how they are coping, to a catalyst for more in depth introspection. I find it a great way to get a group thinking and describing their experience without having to verbally communicate in front of the group. Thus it is suitable for all types of groups, but especially those you take a bit of time to open up and speak their thoughts.

Goal The goals of the finger shoot are:1) To help those who have difficulty articulating their thoughts to find other ways of communicating. 2) For participants to take a stance on the learning that occurred without having heard what others had said first. This can help prevent the "Copy Cat" answer syndrome that can occur during traditional debriefs. 3) To give the facilitator the opportunity to further question participants in order to focus in on important learning issues.

Procedure Like in the game "Paper, scissors, rock", on the count of three, participants hold up any number of fingers ranging from one to five, or one to ten (if using both hands), to evaluate how they performed in some aspect of the experience that they had just been through. For example: As part of the debrief at the conclusion of a bushwalk, you might ask the question; "How would you rate the way you worked together as a team, helping each other through difficult situations?"

All participants hold up their score (fingers). As a facilitator you are now armed with information to further delve into this issue. There are two ways to facilitate this activity from here. You could focus on the negative aspects of their behaviour that had led to their score; ie) "So Joe, you gave yourself a three out of five, what did you do that resulted in giving yourself that score?". Or, you could address the positive "solutions" one would need to take to improve their score. "So Sue, you scored a three out of five. Next time you are in a similar situation what could you do to ensure you scored a four a five?" (See Gass \& Gillis, (1994) for further information on "Solution Focused Facilitation".)

Based on the response of your participants you could then further guide the reflection process with questioning that would attempt to "funnel" the clients learning in a way that could help them discover a path to "functional change". (See Priest \& Naismith, (1992) for more information on funnelling style of questioning.)

Gass, M. Gillis, L. (1994). Focusing on the "solution" rather than the "problem": Empowering client change in adventure experiences. In Proceedings of the Association for Experiential Education's 22nd Annual conference. Austin. Texas. USA AEE publishers. 276-278. 